\title{
Dynamic Characteristics Analysis of H-Type Leg Hydraulic System of Truck mounted Concrete Pump
}

\author{
Liu Huiyong ${ }^{1, a}$, Zhao Qing ${ }^{2, b}$ \\ ${ }^{1}$ College of Mechanical Engineering, Guizhou University, Guiyang, 550025, China \\ ${ }^{2}$ College of Civil Engineering, Guizhou University, Guiyang, 550025, China

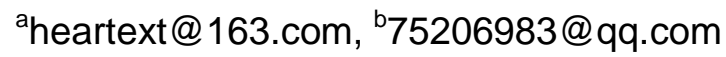

\begin{abstract}
Keywords: H-type leg hydraulic system; Truck mounted concrete pump; Dynamic characteristics; AMESim

Abstract. The leg hydraulic system of truck mounted concrete pump plays an important role in pumping process, and it is necessary to analysis the dynamic characteristics of leg hydraulic system of truck mounted concrete pump. According to the working principle of H-type leg hydraulic system of truck mounted concrete pump, the simulation model of H-type leg hydraulic system is established based on AMESim, and the dynamic characteristics of H-type leg hydraulic system is analyzed. The research result provides some reference for design and improvement of H-type leg hydraulic system of truck mounted concrete pump.
\end{abstract}

\section{Introduction}

Truck mounted concrete pump is a kind of construction machinery by installing concrete pump on the chassis, and combines delivering process and pouring process together. By using truck mounted concrete pump can save time, reduce worker's labor intensity, decrease the consumption of remix concrete, and guarantee the quality of construction. Recently, more and more truck mounted concrete pumps have been widely used in some infrastructure construction engineering, i.e., pipe transport, energy industry, civil building, et al[1]. As an important unit for ensuring the safety and stability of truck mounted concrete pump, H-type leg hydraulic system plays an essential role, and its dynamic characteristics will decide whether a truck mounted concrete pump can work efficiently. Therefore, carrying out the dynamic characteristics analysis of H-type leg hydraulic system is very meaningful.

Zhang Yanwei et al. [2] illustrated the calculation method and formula of leg counter force. Kang Huimei [3] gave calculation method for leg counter force and lift displacement. Tang Yongzhi et al. [4] introduced the design procedure of front legs bear range. Chen Guoan et al. [5] put forward the calculation method for solving the max possible leg counter force. AMESim is an efficient tool for modeling and simulation in some fields including mechanical, pneumatic, magnetic, hydraulic, control, etc. [6], and has been widely used in so many fields such as renewable energy, hydraulic system, hybrid power system, et al.

This paper established the simulation model of the H-type leg hydraulic system of a truck mounted concrete pump based on AMESim according to its working principle, and analyzed its dynamic characteristics. 


\section{Working principle of H-type leg hydraulic system}

As shown in Fig. 1, H-type leg is known for the chassis and 4 legs of truck mounted concrete pump will become the shape of $\mathrm{H}$ after 4 legs are extended, and each leg has one vertical extend/contract cylinder and one horizontal extend/contract cylinder, so the H-type leg hydraulic system of truck mounted concrete pump need $4 \mathrm{leg}$ vertical extend/contract cylinders and $4 \mathrm{leg}$ horizontal extend/contract cylinders. In order to ensure 4 legs have enough extending length, two front legs and two rear legs are staggered on the left and right sides. As shown in Fig. 2, The H-type leg hydraulic system mainly consists of engine, pump, pressure relief valve, bi-directional hydraulic lock, 4 leg vertical extend/contract cylinders and 4 leg horizontal extend/contract cylinders. The leg horizontal extend/contract cylinders (1-4) are used for controlling the legs' extend/contract in horizontal direction, and the leg vertical extend/contract cylinders (5-8) are used for controlling the legs' extend/contract in vertical direction. When the rods of the leg horizontal extend/contract cylinders (1-4) extend to a certain position, the shape made from the chassis and 4 legs is $\mathrm{H}$, then under the action of the leg vertical extend/contract cylinders (5-8) all tires of a truck mounted concrete pump are lifted and leave the ground so as to guarantee it has adequate safety and stability.

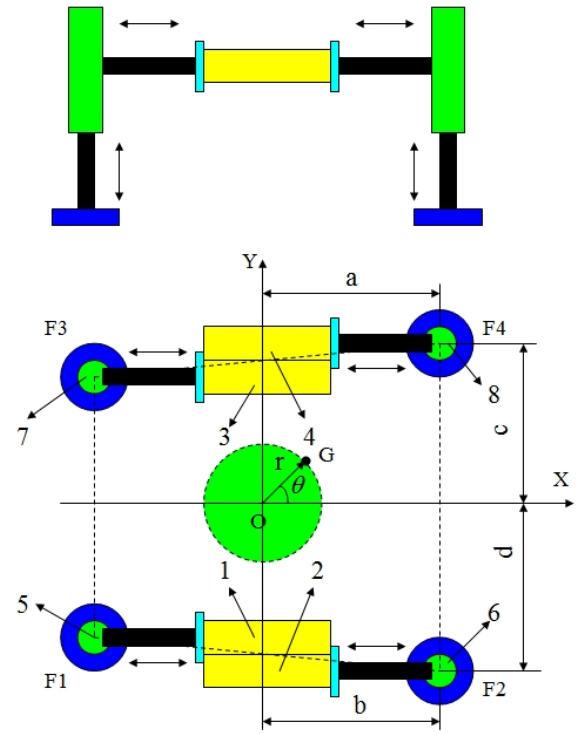

Figure 1 Structure of H-type leg
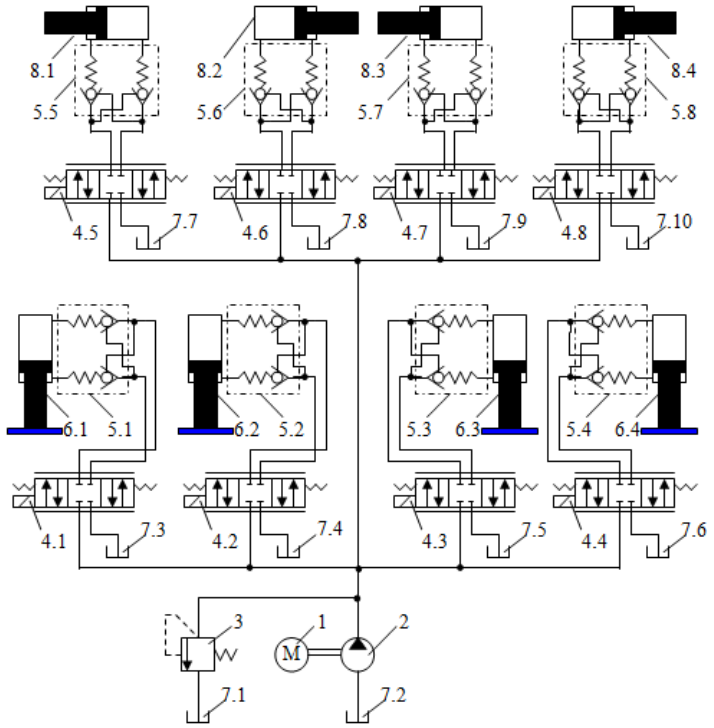

Figure 2 H-type leg hydraulic system

1-engine, 2-pump, 3-pressure relief valve, 4-directional control valve, 5-bi-directional hydraulic lock , 6-leg vertical expand/contract cylinders, 7-tank, 8-leg horizontal expand/contract cylinders

\section{AMESim model of H-type leg hydraulic system}

In modeling environment AMESim, by selecting appropriate model of pump, valve, hydraulic lock and cylinder, etc., the AMESim model of H-type leg hydraulic system is established, as shown in Fig. 3. 


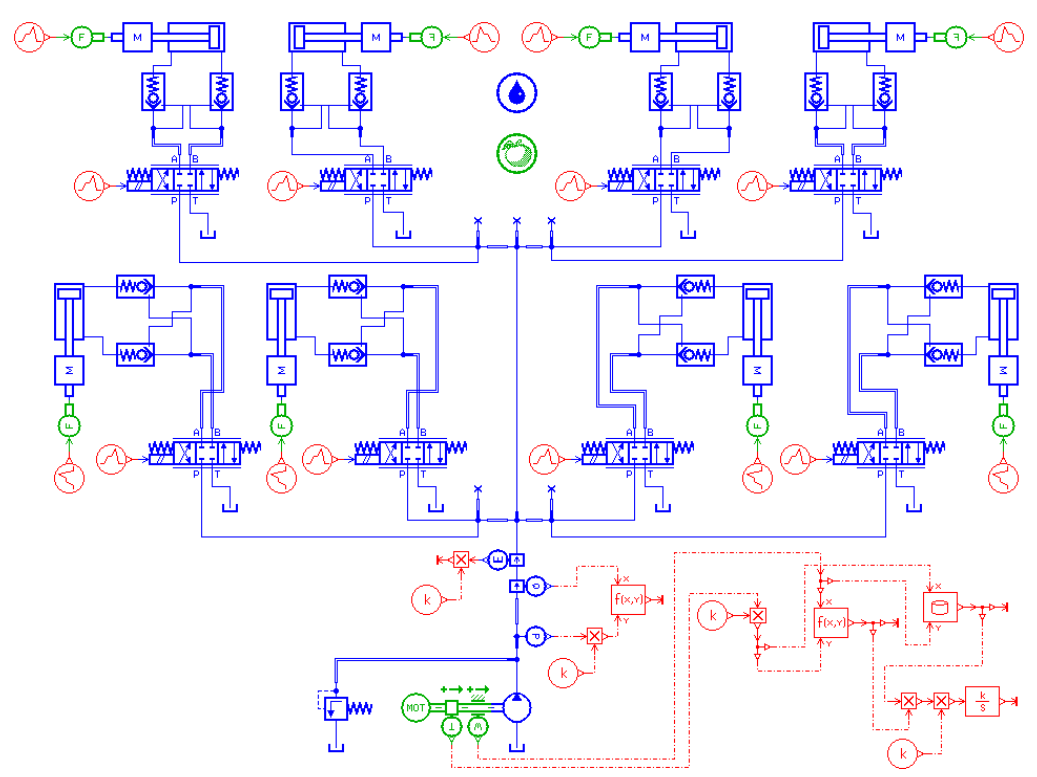

Fig.3 AMESim model of H-type leg hydraulic system

\section{Results and analysis}

The simulation parameters for H-type leg hydraulic system are as follows: For a certain truck mounted concrete pump, weight is $48000 \mathrm{~kg}$, transverse span of left and right legs are $7800 \mathrm{~mm}$ and $9200 \mathrm{~mm}$ respectively, and transverse span of front and rear legs is $7600 \mathrm{~mm}$. The rotational speeds of engine and pump are both $1450 \mathrm{rev} / \mathrm{min}$, and the displacement of pump is $75 \mathrm{cc} / \mathrm{rev}$, the setting pressure of pressure relief valve is $250 \mathrm{bar}$, the open pressure and control pressure of bi-directional hydraulic locks is 0.5 bar and $20 \mathrm{bar}$ respectively. The mass of each front leg and rear leg are $950 \mathrm{~kg}$. The cylinder diameter, rod diameter and stroke of 4 leg horizontal extend/contract cylinders is $160 \mathrm{~mm}, 1190 \mathrm{~mm}$ and $3800 \mathrm{~mm}$ respectively The cylinder diameter, rod diameter and stroke of 4 leg vertical extend/contract cylinders is $180 \mathrm{~mm}, 125 \mathrm{~mm}$ and $800 \mathrm{~mm}$ respectively. The simulation results are shown in Fig. 4-Fig. 9.

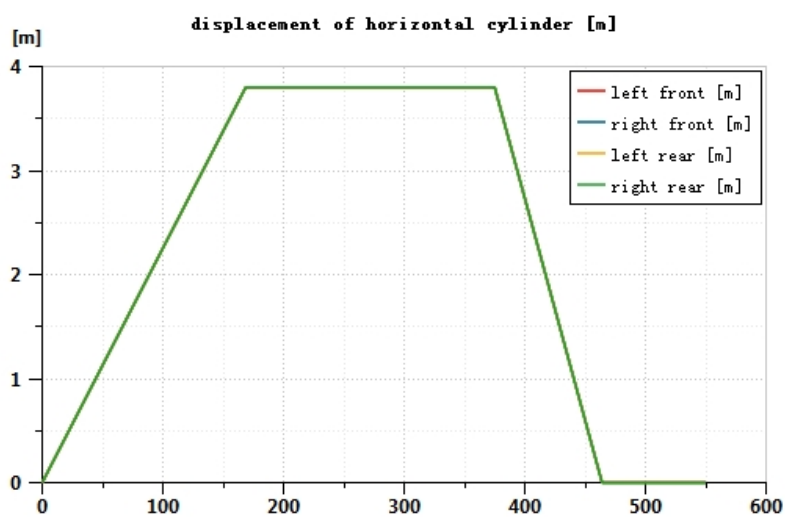

Fig. 4 Displacement of leg horizontal cylinders

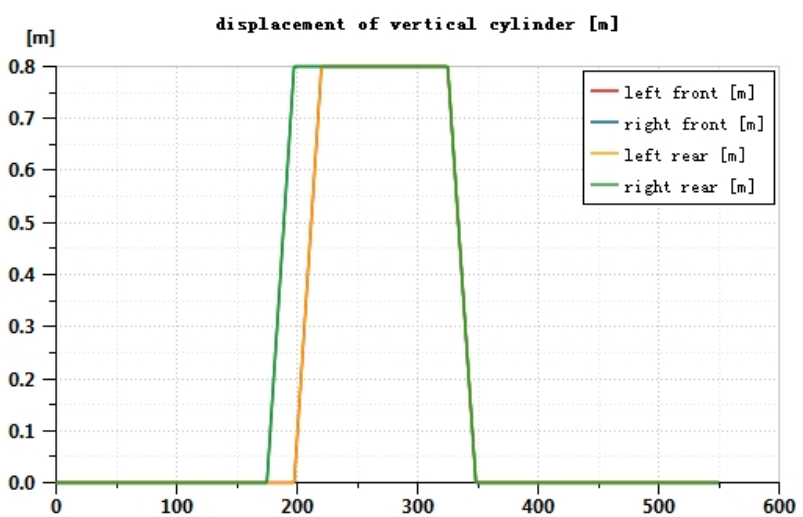

Fig. 5 Displacement of leg vertical cylinders

As shown in Fig. 4, during the extending process of 4 leg horizontal extend/contract cylinders, 4 leg horizontal extend/contract cylinders extend simultaneously to their expected displacement $3.8 \mathrm{~m}$ using $168.71 \mathrm{~s}$, then remain $3.8 \mathrm{~m}$ under the effect of hydraulic locks for $206.4 \mathrm{~s}$. During the contracting process of 4 leg horizontal extend/contract cylinders, 4 leg horizontal extend/contract cylinders contract simultaneously from $3.8 \mathrm{~m}$ to $0 \mathrm{~m}$ using $88.97 \mathrm{~s}$. As shown in Fig. 5, during the extending process of 4 leg vertical extend/contract cylinders, 4 leg vertical extend/contract cylinders extend to their expected displacement $0.8 \mathrm{~m}$ using $22.5 \mathrm{~s}$, but the right leg vertical extend/contract 
cylinders extend from 175s while the left leg vertical extend/contract cylinders extend from 199.5s, which means that the right leg vertical extend/contract cylinders extend earlier than the left leg vertical extend/contract cylinders for 24.5s.During the contracting process of 4 leg vertical extend/contract cylinders from 325.06s, 4 leg vertical extend/contract cylinders contract simultaneously from $0.8 \mathrm{~m}$ to $0 \mathrm{~m}$ using $23.3 \mathrm{~s}$.

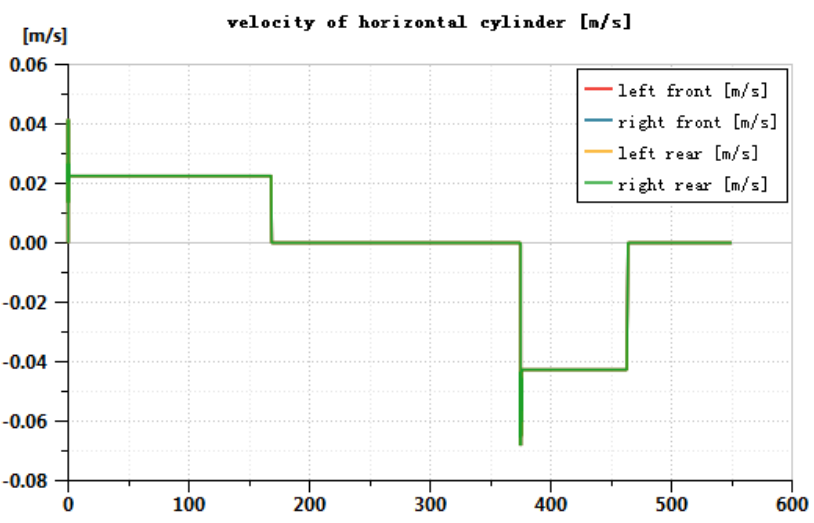

Fig. 6 Velocity of leg horizontal cylinders

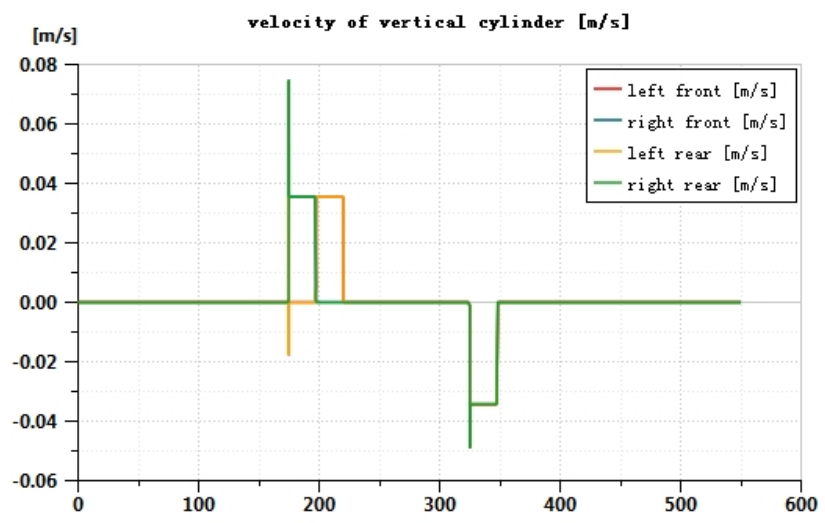

Fig. 7 Velocity of leg vertical cylinders

As shown in Fig. 6, during the extending process of 4 leg horizontal extend/contract cylinders, the velocity of 4 leg horizontal extend/contract cylinders is $0.0225 \mathrm{~m} / \mathrm{s}$ and last $168.71 \mathrm{~s}$, then turns to $0 \mathrm{~m} / \mathrm{s}$ for $206.4 \mathrm{~s}$. During the contracting process of 4 leg horizontal extend/contract cylinders, the velocity of 4 leg horizontal extend/contract cylinders is $0.0427 \mathrm{~m} / \mathrm{s}$ and last $88.97 \mathrm{~s}$. As shown in Fig. 7 , during the extending process of 4 leg vertical extend/contract cylinders, the velocity of the right leg vertical extend/contract cylinders turns from $0 \mathrm{~m} / \mathrm{s}$ to $0.0355 \mathrm{~m} / \mathrm{s}$ at the time of $175 \mathrm{~s}$, then turns to $0 \mathrm{~m} / \mathrm{s}$ at the time of $197.5 \mathrm{~s}$, while the velocity of the left leg vertical extend/contract cylinders turns from $0 \mathrm{~m} / \mathrm{s}$ to $0.0355 \mathrm{~m} / \mathrm{s}$ at the time of $199.5 \mathrm{~s}$, then turns to $0 \mathrm{~m} / \mathrm{s}$ at the time of $220 \mathrm{~s}$.During the contracting process of $4 \mathrm{leg}$ vertical extend/contract cylinders from $325.06 \mathrm{~s}$, the velocity of $4 \mathrm{leg}$ vertical extend/contract cylinders is $0.0343 \mathrm{~m} / \mathrm{s}$ and last $23.3 \mathrm{~s}$.

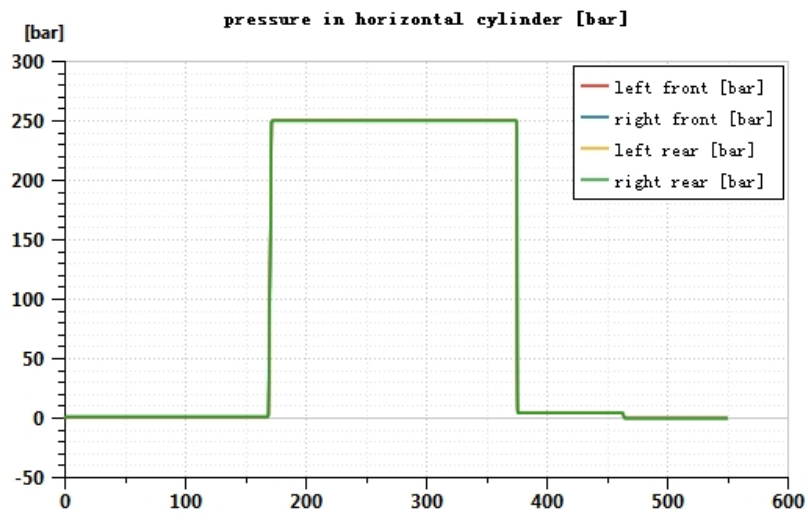

Fig. 8 Pressure in leg horizontal cylinders

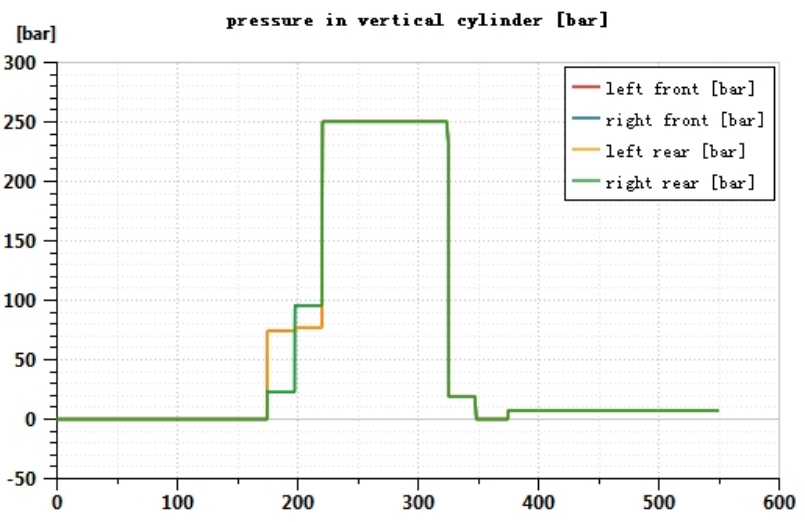

Fig. 9 Pressure in leg vertical cylinders

As shown in Fig. 8, during the extending process of 4 leg horizontal extend/contract cylinders, the pressure of 4 leg horizontal extend/contract cylinders is 1.14 bar and last $168.71 \mathrm{~s}$, then turns to 250 bar for 206.4s. During the contracting process of 4 leg horizontal extend/contract cylinders, the pressure in rodless chambers of 4 leg horizontal extend/contract cylinders is 4.31 bar and last $88.97 \mathrm{~s}$. As shown in Fig. 9, during the extending process of 4 leg vertical extend/contract cylinders, the pressure of the right and left leg vertical extend/contract cylinders turns from Obar to 22.7bar and 74.3 bar respectively at the time of $175 \mathrm{~s}$. After $22.5 \mathrm{~s}$ the pressure of the right and left leg vertical 
extend/contract cylinders turns to $95.65 \mathrm{bar}$ and $77.22 \mathrm{bar}$ using $22.5 \mathrm{~s}$, then turns to $250 \mathrm{bar}$ for 105.06s. During the contracting process of 4 leg vertical extend/contract cylinders, the pressure of 4 leg vertical extend/contract cylinders is 18.89 bar using $23.3 \mathrm{~s}$.

\section{Conclusion}

According to the working principle of concrete pump H-type leg hydraulic system, the simulation model of concrete pump H-type leg hydraulic system is established based on AMESim, and the dynamic characteristics of concrete pump H-type leg hydraulic system is analyzed. The research result provides some reference for design and improvement of concrete pump H-type leg hydraulic system.

\section{Acknowledgement}

This work was supported by the National Natural Science Foundation of China [grant number 51365008]; the Joint Foundation of Science and Technology Department of Guizhou Province [grant number Qiankehe LH Zi[2015]7658]. The authors gratefully acknowledge their support. Additionally, Liu Huiyong acknowledges the financial support from China Scholarship Council (CSC) to visit the Fluid-Structure Interaction Research Group (FSIRG) in the Faculty of Engineering and the Environment at the University of Southampton [grant number 201606675008].

\section{References}

[1] Zhang Guozhong : Modern concrete pump truck and its application technology in construction (China Building Materials Press, China 2004).

[2] CHEN Guoan, ZHU Zhencai, LI Siding: Maximum loading calculation for construction machinery outriggers. CHINESE JOURNAL OF CONSTRUCTION MACHINERY,Vol.8(2) (2010), p. 162-165.

[3] TANG Yongzhi, QUE Shenghua: Optimal design of X-style supports' angle of concrete pump truck. CONSTRUCTION MECHANIZATION, Vol.2 (2011), p. 47-48.

[4]ZHANG yanwei, SUN Guozheng, SHI Laide: Counterforce Calculation and Structure Analysis Method of Concrete Pump's Stabilizers. CHINESE JOURNAL OF CONSTRUCTION MACHINERY,Vol.2(3) (2004), p. 253-258.

[5] KANG Huimei: Analysis of concrete pump truck leg reaction force and the rising height. Construction Machinery Technology \& Management, Vol.4 (2002), p. 7-10.

[6] FU Yongling and QI Xiaoye: System Modeling and Simulation Based on AMESim -- From entry to mastery (BEIHANG UNIVERSITY PRESS, China 2006). 